\title{
Relationship between Aggressive Behaviour and Parenting Style
}

\author{
Vandana Kumari $^{1 *}$ and Tejpreet Kaur Kang ${ }^{2}$ \\ ${ }^{1}$ Department of Home Sciences, Government Girls Post Graduate College, \\ Ghazipur - 233 001, UP, India \\ ${ }^{2}$ Department of Human Development, PAU, Ludhiana -141 004, Punjab, India \\ *Corresponding author email id:
}

\section{A B S T R A C T}

\begin{tabular}{|l|}
\hline Ke y w o r d s \\
Aggression, \\
Indirect aggression, \\
Indulgence \\
Moralism, \\
Negativism, \\
Realism, Suspicion, \\
Verbal aggression. \\
\hline Article Info \\
\hline Accepted: \\
12 April 2017 \\
Available Online: \\
10 May 2017 \\
\hline \hline
\end{tabular}

The present study investigated on how the aggressive behaviour is related to parenting style. The study was conducted on 400 adolescents of Ludhiana district of Punjab state. Buss-Durkee aggression scale, Hindi adaptation by Sultania was used for the assessment of aggressive behaviour of respondents. Parenting scale by Bhardwaj, Sharma and Garg (1998) was used to study parenting style used by parents. Results revealed that boys and girls are equally aggressive but they aggress in different ways. Correlation analysis showed that expression of indirect aggression is negatively and significantly related to acceptance and marital adjustment and positively and significantly related with protection. Irritative behaviour is positively and significantly related with parent's protection. Negative feeling is positively and significantly related to parents' protection, indulgence and realism. Resentment behaviour of adolescents is negatively and significantly related to acceptance and realistic role expectation. Suspicion showed positive and significant relation with protection and discipline. Expression of verbal aggression had positive and significant relation with protecting style and negative and significant relation with realism, moralism, realistic role expectation and marital adjustment. Guilt feeling is found to have negative and significant relation with acceptance of parents. Aggression of adolescents had positive and significant association with protection and negative and significant relation with acceptance and marital adjustment.

\section{Introduction}

Aggressive behaviour is any demanding or intrusive behaviour that has an adverse effect on others (e.g., name calling, taunting, or verbal threats). It can be direct (yelling, destroying personal property, insulting), or indirect (gossiping, ignoring, spreading false rumours). It may be driven by emotional arousal often some form of frustration, or it may be instrumental when it is used to secure a reward. Berkowitz (1993) defined aggression as any form of behaviour that is intended to injure someone physically or psychologically. The dictionary meaning of aggression is hostile or violent behavior or attitudes. It is a disorganized emotional response. Operationally aggression may be defined in terms of frequent quarreling, impulses of taking revenge and reactionary attitudes to traditions and beliefs. It is considered as a learned behavior or as an act against frustration which is affected by various biological and environment factors. 
Family is a basic and universal institution. Parenting happens to be one of the most important roles of the family. Parenting has been defined as a single minded unconditional desire to provide a loving and caring home. Parents also influence their children in every aspect of their lives particularly in adolescence period; in the type of parenting approach they adopt to rear their child. Parenting style is defined as the manner in which parents treat, communicate, discipline, monitor and support their children (Slicker and Thornberry, 2003). When parents are warm, protective and supportive, children are unlikely to be over aroused and are better able to respond to parental efforts to focus their attention and guide their behaviour. This view is consistent with Vygotsky's (1978) view that cognitive skills are socially constructed through interactions with supportive and responsive adults. Parenting styles may also be linked to children's regulation and externalizing behaviour problems because of its effects on the quality of the parent-child relationship. Parental warmth and acceptance, positive expressivity and protection have been linked to a secure attachment (Contreras et al., 2000) and this security is believed to foster regulated behaviour, because child has greater psychological resources for dealing with negative emotions and events. In addition children with more secure attachment are likely to be better at understanding others' emotions (Laible and Thompson, 2002), all of which could result in greater emotional control of behaviour and lower levels of aggressive behaviour. Keeping in view of the above the study was planned to investigate the relationship between aggressive behaviour and parenting style.

\section{Materials and Methods}

The sample comprised of 400 adolescents (200 boys and 200 girls) were selected from different schools of Ludhiana district of
Punjab. Those adolescents were purposely selected to constitute the sample that were of Punjabi origin and belonged to nuclear and intact families.

Buss-Durkee Aggression scale was used for the assessment of aggressive behaviour of respondents. It is a self-report type of test which measures general aggression as well as various forms of aggression, such as assault, indirect aggression, irritability, negativism, resentment, suspicion, verbal aggression and guilt. The Hindi adaptation was done by Sultania (2006) for Hindi speaking population/sample. The scale consists of 67 items which measure eight forms of aggression like assault, indirect aggression, irritability, negativism, resentment, suspicions, verbal aggression and guilt. The inventory includes 59 items that measure hostility and 8 items measure guilt. Parenting scale by Bhardwaj et al., (1998) was used to study parenting style used by parents as perceived by adolescents.

\section{Results and Discussion}

The results of table 1 depict the gender differentials in level of various dimensions of aggression among adolescents. The perusal of table reveals that only significant difference was found on account of total aggression. Seventy three per cent boys expressed medium level of aggression while 57 per cent girls exhibited medium level of aggression. The result is supported by findings that males are quicker to aggression (Frey, 2003; Coie and Dodge, 1997; Maccoby and Jacklin, 1974) and more likely than females to express their aggression physically (Bjorkqvist et al., 1994). Furthermore, there are gender differences in the seriousness of aggression. Males are more likely than females to commit more serious acts of aggression. Hadley (2003) studied male versus female aggression and concluded that males are more aggressive 
than females and from about four years of age onwards boys are more likely than girls to engage in aggressive and non- aggressive antisocial behaviour.

No significant difference was found in various dimensions of aggression. The result is in contrast with study of Crick and Grotpeter (1995) which showed that males and females are equally aggressive but they aggress in different ways with males using physical aggression more than females, and females using indirect or relational aggression more than males. Saudino (2003) reported that females are not necessarily less aggressive but they tend to show their aggression in less overt, less physical ways. Aggression in girls is often overlooked because it takes an indirect form. Women generally cope with anger and frustration in less violent ways. Women might mask their aggression through manipulation, silence, and exaggerated sweetness. However, over time, such coping mechanisms, can lead to depression, disconnected relationships or even numbing behaviours such as overeating, drinking or drug use. Investigators have succeeded in disconfirming the long held belief that males are more aggressive females (Buss, 1961; Maccoby and Jacklin, 1974). Studies have shown that males and females aggress in different ways with males using physical aggression more than females, and females using indirect or relational aggression more than males (Crick and Grotpeter, 1995, Lagerspetz et al., 1988).

\section{Percent distribution of adolescents across various modes of parenting}

Table 2 displays percent distribution of adolescents across eight dimensions of parenting style. In case of boys 41.5 per cent adolescents were moderately accepted by their parents, while 52.5per cent were highly accepted. It indicated that parents had positive attitude towards their adolescent boys and showed acceptance for their ideas and judgment. Only six per cent adolescent boys were moderately rejected by their parents. In case of girls, majority (62.5\%) was highly accepted by their parents and only five per cent were moderately rejected. Their parents were found to be loving, affectionate and had attentive behaviour towards needs of their adolescent girls. Among adolescents, 57.5per cent were highly accepted and only 5.5per cent were moderately rejected by their parents. This table further depicts that 36.5per cent adolescent boys were moderately protected while 61 per cent were highly protected by their parents. This shows over indulgence and uncared pampering of parents. The perusal of table reveals that percentage of girls $(70.5 \%)$ in high level of protection was more as compared to boys. Among adolescents 32per cent were moderately protected by their parents while 65.75 per cent were highly protected. The table further depicts that in case of boy adolescents 43per cent parents showed moderate level of indulging behavior as compared to 27.5 per cent of girls. While proportion of girl's parents $(71.5 \%)$ were more as compared to boys' parents (54\%). Among adolescents 35.25 per cent reported that their parents were moderately indulged while 62.75per cent reported of high indulgence. It indicates that majority of parents were failure to exercise needed constraints and they are highly attentive towards the need of adolescents.

In case of boy adolescents, 55.5per cent of parents had moderate level of expectations by considering the limits of adolescents while 38 per cent parents had highly realistic expectation from their boy adolescents. In case of girls 60per cent parents expect moderate level of expectations and 37.5per cent expected highly realistic expectations. Among adolescents 57.75per cent expected moderate level of realistic expectations and 
37.75per cent had high level of real expectations. In the dimension of moralism 45per cent parents believed in moderate level of moralism while 52.5per cent believed in high level in case of boy adolescents. While in case of girls the more proportion of parents (70 \%) believed in high level of moralism as compared to boy adolescents. Among adolescents, 36.75per cent parents believed in moderate level of moralism while 61.25per cent believed in high level. It indicated that parents wanted that their adolescents must learn moral values and should satisfy their superego by abiding the rules of society. In contrast to these parents believe in moderate level of discipline (58\%) and high level of discipline $(34.5 \%)$ for adolescent boys. While in case of girls 53 per cent parents believed in moderated level of discipline and 38.5per cent in high level discipline. Among adolescents around 55per cent parents believed in moderated level of discipline while 36.5per cent believed in high level of discipline.

Table.1 Gender differentials in three levels of various dimensions of aggression

\begin{tabular}{|c|c|c|c|c|}
\hline $\begin{array}{c}\text { Dimensions of } \\
\text { Aggression }\end{array}$ & $\begin{array}{c}\text { Levels of } \\
\text { Aggression }\end{array}$ & $\begin{array}{c}\text { (Boys) } \\
(\mathbf{n}=\mathbf{2 0 0})\end{array}$ & $\begin{array}{c}\text { (Girls) } \\
(\mathbf{n}=200)\end{array}$ & $Z$ value \\
\hline \multirow{3}{*}{ Assault } & Low & $21(10.5)$ & $34(17)$ & -1.335 \\
\hline & Medium & $141(70.5)$ & $140(70)$ & 0.0779 \\
\hline & High & 38 (19) & $26(13)$ & 1.157 \\
\hline \multirow{3}{*}{$\begin{array}{c}\text { Indirect } \\
\text { Aggression }\end{array}$} & Low & $19(9.5)$ & $18(9)$ & 0.122 \\
\hline & Medium & $137(68.5)$ & $150(75)$ & -1.021 \\
\hline & High & $44(22)$ & $32(16)$ & 1.081 \\
\hline \multirow{3}{*}{ Irritability } & Low & $17(8.5)$ & $25(12.5)$ & -0.923 \\
\hline & Medium & $157(78.5)$ & $137(68.5)$ & 1.602 \\
\hline & High & $26(13)$ & $38(19)$ & -1.157 \\
\hline \multirow{3}{*}{ Negativism } & Low & $39(19.5)$ & $49(24.5)$ & -0.853 \\
\hline & Medium & $122(61)$ & $121(60.5)$ & 0.072 \\
\hline & High & $39(19.5)$ & $30(15)$ & 0.842 \\
\hline \multirow{3}{*}{ Resentment } & Low & $25(12.5)$ & $17(8.5)$ & 0.923 \\
\hline & Medium & $89(44.5)$ & $81(40.5)$ & 0.572 \\
\hline & High & $86(43)$ & $102(51)$ & -1.133 \\
\hline \multirow{3}{*}{ Suspicion } & Low & $23(11.5)$ & $23(11.5)$ & 0.000 \\
\hline & Medium & $168(84)$ & $158(79)$ & 0.911 \\
\hline & High & $9(4.5)$ & $19(9.5)$ & -1.386 \\
\hline \multirow{3}{*}{ Verbal Aggression } & Low & $46(23)$ & $59(29.5)$ & -1.045 \\
\hline & Medium & $111(55.5)$ & $115(57.5)$ & -0.285 \\
\hline & High & $43(21.5)$ & $26(13)$ & 1.591 \\
\hline \multirow{3}{*}{ Guilt } & Low & $28(14)$ & $16(8)$ & 1.356 \\
\hline & Medium & $152(76)$ & $160(80)$ & -0.683 \\
\hline & High & $20(10)$ & $24(12)$ & -0.452 \\
\hline \multirow{3}{*}{ Total Aggression } & Low & $22(11)$ & $35(17.5)$ & -1.315 \\
\hline & Medium & $146(73)$ & $114(57)$ & $2.372 * *$ \\
\hline & High & $32(16)$ & $37(18.5)$ & -0.468 \\
\hline
\end{tabular}

Significant at $10 \%$ level of significance; $* *$ Significant at $5 \%$ level of significance; *** Significant at $1 \%$ level of significance 
Table.2 Percent distribution of adolescents across various modes of parenting

\begin{tabular}{|c|c|c|c|c|c|c|c|c|c|c|c|c|}
\hline \multirow[t]{2}{*}{ Dimensions } & \multicolumn{4}{|c|}{ BOYS } & \multicolumn{4}{|c|}{ GIRLS } & \multicolumn{4}{|c|}{ TOTAL } \\
\hline & $\mathbf{M}$ & $\%$ & $\mathbf{H}$ & $\%$ & $\mathbf{M}$ & $\%$ & $\mathbf{H}$ & $\%$ & $\mathbf{M}$ & $\%$ & $\mathbf{H}$ & $\%$ \\
\hline \multirow{2}{*}{$\begin{array}{l}\text { Rejection } \\
\text { Acceptance }\end{array}$} & 12 & 6 & 0 & 0 & 10 & 5 & 0 & 0 & 22 & 5.5 & 0 & 0 \\
\hline & 83 & 41.5 & 105 & 52.5 & 65 & 32.5 & 125 & 62.5 & 148 & 37 & 230 & 57.5 \\
\hline \multirow{2}{*}{$\begin{array}{c}\text { Carelessness } \\
\text { Protection }\end{array}$} & 5 & 2.5 & 0 & 0 & 4 & 2 & 0 & 0 & 9 & 2.25 & 0 & 0 \\
\hline & 73 & 36.5 & 122 & 61 & 55 & 27.5 & 141 & 70.5 & 128 & 32 & 263 & 65.75 \\
\hline \multirow{2}{*}{$\begin{array}{c}\text { Neglect } \\
\text { Indulgence }\end{array}$} & 6 & 3 & 0 & 0 & 2 & 1 & 0 & 0 & 8 & 2 & 0 & 0 \\
\hline & 86 & 43 & 108 & 54 & 55 & 27.5 & 143 & 71.5 & 141 & 35.25 & 251 & 62.75 \\
\hline \multirow{2}{*}{$\begin{array}{c}\text { Utopian expectation } \\
\text { Realism }\end{array}$} & 13 & 6.5 & 0 & 0 & 5 & 2.5 & 0 & 0 & 18 & 4.5 & 0 & 0 \\
\hline & 111 & 55.5 & 76 & 38 & 120 & 60 & 75 & 37.5 & 231 & 57.75 & 151 & 37.75 \\
\hline \multirow{2}{*}{$\begin{array}{c}\text { Lenient standard } \\
\text { Moralism }\end{array}$} & 5 & 2.5 & 0 & 0 & 3 & 1.5 & 0 & 0 & 8 & 2 & 0 & 0 \\
\hline & 90 & 45 & 105 & 52.5 & 57 & 28.5 & 140 & 70 & 147 & 36.75 & 245 & 61.25 \\
\hline \multirow{2}{*}{$\begin{array}{l}\text { Freedom } \\
\text { Discipline }\end{array}$} & 15 & 7.5 & 0 & 0 & 17 & 8.5 & 0 & 0 & 32 & 8 & 0 & 0 \\
\hline & 116 & 58 & 69 & 34.5 & 106 & 53 & 77 & 38.5 & 222 & 55.5 & 146 & 36.5 \\
\hline \multirow{2}{*}{$\begin{array}{c}\text { Faulty role expectation } \\
\text { Realistic role } \\
\text { expectation }\end{array}$} & 15 & 7.5 & 0 & 0 & 8 & 4 & 0 & 0 & 23 & 5.75 & 0 & 0 \\
\hline & 103 & 51.5 & 82 & 41 & 99 & 49.5 & 93 & 46.5 & 202 & 50.5 & 175 & 43.75 \\
\hline \multirow{2}{*}{$\begin{array}{c}\text { Marital conflict } \\
\text { Marital adjustment }\end{array}$} & 6 & 3 & 0 & 0 & 0 & 0 & 1 & 0.5 & 6 & 1.5 & 1 & 0.25 \\
\hline & 99 & 49.5 & 95 & 47.5 & 68 & 34 & 131 & 65.5 & 167 & 41.75 & 226 & 56.5 \\
\hline
\end{tabular}

M: Moderate; H: high 
Table.3 Correlation analysis between aggression and parenting style among adolescents

\begin{tabular}{|c|c|c|c|c|c|c|c|c|c|}
\hline $\begin{array}{l}\text { Dimension of } \\
\text { parenting style }\end{array}$ & Assault & $\begin{array}{l}\text { Indirect } \\
\text { Aggression }\end{array}$ & Irritability & Negativism & Resentment & Suspicion & $\begin{array}{l}\text { Verbal } \\
\text { Aggression }\end{array}$ & Guilt & $\begin{array}{l}\text { Total } \\
\text { Aggression }\end{array}$ \\
\hline A & -0.021 & $-0.121 * *$ & -0.011 & 0.065 & $-0.103 * *$ & -0.019 & -0.078 & $-0.095^{*}$ & $-0.102 * *$ \\
\hline B & 0.031 & $0.090 *$ & $0.117 * *$ & $0.103 * *$ & 0.068 & $0.099 * *$ & $0.105 * *$ & 0.048 & $0.165^{* * *}$ \\
\hline $\mathrm{C}$ & 0.059 & -0.044 & 0.039 & $0.090 *$ & -0.037 & -0.012 & -0.040 & -0.018 & 0.004 \\
\hline $\mathrm{D}$ & 0.067 & -0.054 & -0.043 & $0.106 * *$ & $0.092 *$ & 0.061 & $-0.196 * * *$ & -0.055 & -0.002 \\
\hline $\mathrm{E}$ & -0.003 & -0.032 & 0.045 & 0.078 & -0.030 & -0.027 & $-0.171 * * *$ & 0.074 & -0.023 \\
\hline $\mathrm{F}$ & -0.017 & 0.003 & 0.080 & 0.004 & -0.038 & $0.088 *$ & 0.050 & 0.032 & 0.051 \\
\hline $\mathrm{G}$ & 0.082 & -0.029 & -0.054 & -0.029 & $-0.087 *$ & 0.015 & $-0.104 * *$ & -0.053 & -0.062 \\
\hline $\mathrm{H}$ & 0.013 & $-0.194 * * *$ & -0.002 & -0.040 & -0.074 & 0.064 & $-0.208 * * *$ & -0.016 & $-0.112 * *$ \\
\hline
\end{tabular}

A: Acceptance; B: Protection; C: Indulgence; D: Realism; E: Moralism; F: Discipline; G: Realistic role expectation; H: Marital adjustment

$*$ Significant at $10 \%$ level of significance; ** Significant at $5 \%$ level of significance; *** Significant at $1 \%$ level of significance 
In case of boys 51.5 per cent parents displayed moderate level of realistic role expectation while 41per cent displayed high level of realistic role expectation showing that they had consistency in their thoughts and actions and considered themselves as an inspiring model for their adolescent boys. In case of girls nearly equal portion of parents $(49.5 \%$ and $46.5 \%)$ believed in moderate and high level of realistic role expectation.

Adolescent boys revealed good impact of parents' marital relationship (49.5per cent) on adolescents' life, while in case of girls; proportion of parents in high level (65.5per cent) marital adjustment was more as compared to boy adolescents. Among adolescents, 41.75per cent parents had moderate and 56.5per cent had high level of marital adjustment in their lives.

\section{Correlation analysis between aggression and parenting style among adolescents}

Table 3 shows correlation analysis between aggression and parenting style among adolescents. The perusal of table reveals assaultive behaviour of adolescents is not significantly related to parenting style. Expression of indirect aggression is negatively and significantly related to acceptance $(r=$ $0.121, \mathrm{p}<0.05)$ and marital adjustment $(\mathrm{r}=$ $0.194, p<0.01$ ) and positively and significantly related with protection $(\mathrm{r}=0.090, \mathrm{p}<0.10)$. The result is consistent with finding of Caspi et al., (2004) that parenting styles adopted by parents play a vital role in the development of the children. Parental warmth, acceptance and support are associated with relatively low levels of children's aggressive behaviour.

Irritative behaviour of adolescents showed positive and significant relation with parent's protection $(\mathrm{r}=0.117, \mathrm{p}<0.05)$. The reason could be that at adolescence stage, children seek freedom from parents so parents' over protection make them feel irritated. Adolescents' negativism is positively and significantly related to parents' protection ( $\mathrm{r}=$
0.103, $\mathrm{p}<0.05)$, indulgence $(\mathrm{r}=0.090, \mathrm{p}<0.10)$ and realism $(\mathrm{r}=0.106, \mathrm{p}<0.05)$. The result is consistent with findings of Mithas (1997) who reported that emotional competence was found to be greater in those early adolescents who perceive their parenting as imbued with utopian expectations than that of realism. Resentment behaviour of adolescents is negatively and significantly related to acceptance $(r=-0.103$, $\mathrm{p}<0.05)$ and realistic role expectation $(\mathrm{r}=$ $0.087, \mathrm{p}<0.10)$. Suspicion showed positive and significant relation with protection $(\mathrm{r}=0.099, \mathrm{p}<$ $0.05)$ and discipline $(r=0.088, p<0.10)$. The result is consistent with findings of Gershoff (2002) who reported that discipline in terms of corporal punishment by parents had a robust relationship with aggression.

Expression of verbal aggression had positive and significant relation with protecting style $(\mathrm{r}=$ $0.105, \mathrm{p}<0.05)$ and negative and significant relation with realism $(\mathrm{r}=-0.196, \mathrm{p}<0.01)$, moralism $(\mathrm{r}=-0.171, \mathrm{p}<0.01)$, realistic role expectation $(\mathrm{r}=-0.104, \mathrm{p}<0.05)$ and marital adjustment $(\mathrm{r}=-0.208, \mathrm{p}<0.01)$. The result is consistent with findings of Mithas (1997) that emotional competence was found to be greater in those early adolescents who perceive their mothering and fathering as associated with realistic role expectations than that of faulty role expectations. Guilt feeling is found to have negative and significant relation with acceptance $(r=-0.095, p<0.10)$ of parents. Aggression of adolescents had positive and significant association with protection $(\mathrm{r}=$ $0.165, \mathrm{p}<0.01$ ) and negative and significant relation with acceptance $(\mathrm{r}=-0.102, \mathrm{p}<0.05)$ and marital adjustment $(\mathrm{r}=-0.112, \mathrm{p}<0.05)$. The result is in line with study of David (1960) that family tensions promote delinquent behaviour. Long term family tensions may reduce the cohesiveness and affect the parent's ability to provide an atmosphere conducive to satisfactory child rearing and solving the problems of the family.

It can be concluded that aggressive behaviour is significantly related to parenting style adopted by parents. Indirect aggression, irritability, 
negativism, suspicion and verbal aggression is positively related to over protection of parents while negatively related to acceptance and marital adjustment. The study was confined only to the adolescents of Ludhiana district of Punjab. The methodology of the present study may be adopted to replicate a research study with a larger sample for better generalization of the findings.

\section{References}

Berkowitz, L. 1993. Aggression: Its causes, consequences and control, Temple University Press, Philadelphia PA.

Bhardwaj, R.L., Sharma, H. and Garg, A. 1998. Parenting scale. Pankaj Mapan, Agra, India.

Bjorkqvist, K., Kirsti, M., Lagerspetz and Osterman, K. 1994. Sex Differences in covert aggression. Aggressive Behavior, 202: 27-33.

Buss, A.H. 1961. The psychology of aggression, New York, Wiley.

Coie, J.D. and Dodge, K.A. 1997. Aggression and antisocial behariour. In: W Damon (Ed.) and N. Eisenberg (Ed.) Handbook of Child psychology: Social emotional and personality development. Wiley Publication, New York.

Crick, N.R. and Grotpeter N.E. 1995. Relational aggression, gender and social psychological adjustment. Child Develop., 66: 710-722.

Frey, S. 2003. Physical aggression in the family and preschoolers. Dev. Psychol., 49: 15568.

Gershoff, E.T. 2002. Corporal punishment by parents and associated child behaviours and experiences: A meta-analytic and theoretical review. Psychol. Bull., 128: 539-579.

Hadley, S. 2003. Male verses female aggression.www.handinhandparenting.or $\mathrm{g} / \mathrm{cs}$ Articles.htm.

Lagerspetz, K.M.J., Bjorkqvist, K. and Peltonen, T. 1988. Is indirect aggression typical of females? Gender differences in aggressiveness in 11-to-12 years old children. Aggressive Behavior, 14: 403414.

Laible, D.J. and Thompson, R. 2002. Mother Child Conflict in the toddler years: Lessons in emotion, morality and relationship. Child Develop., 73: 11871203.

Maccoby, E.E. and Jacklin, C.N. 1974. The psychology of sex differences: Stanford University Press, Stanford, CA.

Mithas, U.J. 1997. Parenting models and sex as correlates of emotional competence among early adolescent labourer and nonlabourers. Doctoral Dissertation (Unpublished), Dr. B.R. Arnbedkar University, Agra.

Saudino, V. 2003. Sex differences in aggression and their way of expression. Pediatrics, 114: 43-50.

Slicker, W.K. and Thornberry, I. 2003. Older adolescent well- being and authoritative and parenting. Adolescent and Family Health, 39: 9-10.

Sultania, M.K. 2006. Aggression Inventory. National Psychological Corporation, Agra.

Vygotsky, L.S. 1978. Mind in Society. Harvard University Press. Cambridge M.A.

\section{How to cite this article:}

Vandana Kumari and Tejpreet Kaur Kang. 2017. Relationship between Aggressive Behaviour and Parenting Style. Int.J.Curr.Microbiol.App.Sci. 6(5): 1224-1231.

doi: https://doi.org/10.20546/ijcmas.2017.605.132 